\title{
The development of hearing abilities in the shark Scyliorhinus canicula
}

\author{
Eric Parmentier ${ }^{1}$ (D) | Marine Banse ${ }^{1}$ | Renaud Boistel ${ }^{2}$ | Philippe Compère $^{1}$ | \\ Frédéric Bertucci $^{1}$ | Orphal Colleye ${ }^{1}$
}

${ }^{1}$ Laboratory of Functional and Evolutionary Morphology, AFFISH-RC, University of Liege, Liège, Belgium

${ }^{2}$ UFR SFA, iPHEP, UMR CNRS 7262,

Université de Poitiers, Poitiers, France

Correspondence

Eric Parmentier, Laboratory of Functional and Evolutionary Morphology, AFFISH-RC, University of Liege, Liège, Belgium.

Email: E.Parmentier@uliege.be

Funding information

Fonds De La Recherche Scientifique - FNRS, Grant/Award Number: T.0192.20 - PDR

\begin{abstract}
The few works on audition in sharks and rays concern only adult specimens. We report the hearing abilities in the dogfish Scyliorhinus canicula at different stages, from embryos that still have their yolk sac inside their egg, to juveniles. Hearing development corresponds to an increase in the frequency range from $100-300 \mathrm{~Hz}$ in early pre-hatching stages to $100-600 \mathrm{~Hz}$ in juveniles. Modifications in hearing abilities correspond to the development of the brain, the increase of the volume of the membranous labyrinth, the growth of the sensory epithelium, and the development of stereocilia in addition to kinocilium before hatching. This work offers solid insights into the development of hearing abilities that usually can only be inferred from the anatomy of vertebrates or after birth/hatching. It shows also that shark can be sensitive to background noise during development.

KEYWORDS

audition, dogfish, labyrinth, macula, ontogeny
\end{abstract}

\section{1 | INTRODUCTION}

Hearing abilities in sharks, skates and rays have been measured for approximately 10 elasmobranch species, in contrast to more than 100 bony fish species (Ladich and Fay, 2013). All tested elasmobranchs cannot detect sounds above $1 \mathrm{kHz}$ (Ladich and Fay, 2013).

The morphology and functional anatomy of the inner ear of elasmobranchs have already been described in different species (Löwenstein and Sand, 1940; Lowenstein and Roberts, 1951; Tester et al., 1972; Barber and Emerson, 1980; Corwin, 1981a; Maisey, 2001; Lovell et al., 2007). Each inner ear can be divided into two parts forming a membranous labyrinth. The upper part consists of three semicircular canals (Barber and Emerson, 1980; Maisey, 2001; Lovell et al., 2007; Mills et al., 2011) that are each associated with an ampulla housing both supporting cells and hair cells grouped in a sensory epithelium called crista (Montgomery et al., 2006; Lovell et al., 2007). In addition, elasmobranchs possess a fourth canal (the endolymphatic duct) that connects the membranous labyrinth of the inner ear to the external environment (Tester et al., 1972; Mills et al.,
2011). The lower part of the inner ear is made up of three chambers (i.e. the saccule, lagena, utricle) that contain thousands of sensory hair cells forming the sensory macula (Lowenstein and Roberts, 1951; Corwin, 1981a; Maisey, 2001). These maculae are overlain by calcium carbonate granules or otoconia (Tester et al., 1972; Corwin, 1989) that act as an inertial mass to stimulate the hair cells (Tester et al., 1972; Hueter et al., 2004). Besides this otolithic-pathway, elasmobranchs possess an additional end organ, the sensory macula neglecta, located in the posterior canal duct in the dorsal portion of the saccule (Retzius, 1884; Corwin, 1981a).

Oviparous females of the lesser-spotted dogfish, Scyliorhinus canicula (Linnaeus, 1758) lay quadrangular horny eggshells provided with tendrils that allow their attachment to weed or stones. Eggs incubate for about 6-8 months. The development, from fertilisation to hatching, can be divided into 34 stages (Ballard et al., 1993). At the beginning of the development, the oxygen needs of the embryo are satiated thanks to the permeability of the eggshell to water (Kormanik, 1993). At about 3-4 months (about 40 mm long), the embryo becomes more active in its eggshell and simple oxygen 
diffusion through the shell is not sufficient. Pre-hatching then consists in the early opening of the eggshell (Demski et al., 1973). This allows the flow of water into the shell to increase the uptake of oxygen (Diez and Davenport, 1987). At the pre-hatching stage, it is experimentally possible to culture the embryo and its yolk sac in sea water outside the eggshell (Foulley and Mellinger, 1980). Definitive hatching finally occurs about 3 or 4 months after pre-hatching, at a size of 90-100 mm (Ballard et al., 1993; Mellinger, 1994).

This pre-hatching phenomenon provides an exceptional opportunity to follow the early development of the inner ear without damaging the fish. We investigated the physiological aspects of the auditory system in the small-spotted dogfish S. canicula using different developmental stages (i.e. from early embryos to juveniles), and we also studied the morphological development in the same specimens.

\section{2 | MATERIALS AND METHODS}

All procedures and methods were approved by the ethical commission of the University of Liège (ethics case 1677).

\section{1 | Acquisition and maintenance of sharks}

The different developmental stages (i.e. 31, 33 and 34) were identified according to the study by Ballard et al. (1993). A total of 26 individuals (total length, TL: $50-465 \mathrm{~mm}$ ) were used in this study. Twenty-one pre-hatchling embryos, from stage 31 (50-62 mm TL), stage 33 (65-90 mm TL) and stage 34 (90-105 mm TL), were obtained from the Sea Life Centre and the Roscoff Marine Station. In addition, five juveniles (340-465 mm TL) were obtained from the Aquarium Dubuisson. Eggs and juveniles were maintained at the ULiège facilities (Belgium) in tanks $(0.6 \times 0.7 \times 1.5 \mathrm{~m})$ filled with saltwater maintained at $16.9^{\circ} \mathrm{C}$. These tanks were equipped with a sand bottom and external filters. No internal filters or air stones were used in order to create a quiet acoustic environment. Sharks were kept under a 12:12 hr L:D photoperiod, and juveniles were fed with squid every day. All individuals were held for 1-3 days before being tested.

\section{2 | Auditory-evoked potential threshold measurement: experimental set-up}

The auditory-evoked potential (AEP) technique directly measures nerve impulses created in the eighth nerve, and activity of the brainstem evoked by acoustic stimuli (Bullock and Corwin, 1979; Corwin and Northcutt, 1982). The presence or absence of a response to sounds of different intensities and frequencies allows the measurement of AEP thresholds. The experimental set-up was similar to that used for previous studies (Parmentier et al., 2009; Colleye et al., 2013; Kéver et al., 2014). No anaesthetics or neuromuscular-blocking drugs were used during the AEP recordings. However, all individuals (embryos and juveniles) were restrained in a custom-made device in order to prevent electrodes dislodging, limiting body and tail movements while allowing normal ventilation. Note that embryos were removed from their eggshell for the experiment. Three subdermal stainless-steel needle electrodes (Rochester Electro-Medical) were used for recording the AEP signal. These electrodes were coated with nail polish so that only $\sim 1 \mathrm{~mm}$ of metal was exposed at the tip. The recording electrode was inserted about 1-2 $\mathrm{mm}$ into the head over the otic region, the reference electrode was inserted into the epaxial musculature, and the ground electrode was placed in the tank water near the shark. All AEP recordings were carried out in a steel barrel (0.78 $\mathrm{m}$ high, $0.48 \mathrm{~m}$ diameter, $3 \mathrm{~mm}$ thickness) oriented vertically, closed at the bottom and opened the upper part. The steel barrel was filled with saltwater $\left(T=16.9^{\circ} \mathrm{C}\right)$ up to a height of $0.73 \mathrm{~m}$, and the test specimen was suspended $20 \mathrm{~cm}$ below the water surface with the head placed at the centre of the circle. So, the head shark was about $0.5 \mathrm{~m}$ above the loudspeaker (UW-30, Lubell Labs) placed on a rubber support on the bottom of the experimental tank. The entire set-up was enclosed in a walk-in soundproof booth (interior dimensions: $1.8 \times 1.8 \times 2.1 \mathrm{~m}$ ).

\subsection{Stimulus generation and AEP recordings}

All hearing is based on mechanosensory hair cells transducing vibrations (and not pressure) into electrical signals (Nedelec et al., 2016). It has already been demonstrated that fish species without swim bladders also lack sound pressure sensitivity (Popper and Fay, 2011; Ladich and Fay, 2013). However, sound pressure is always associated with particle motion (Gans, 1992), meaning the sonic stimuli can be used to highlight the ability to detect different frequencies.

The presentation of sound stimuli and the determination of thresholds followed the detailed description given by Parmentier et al. (2009). Stimuli were tone bursts of $50 \mathrm{~ms}$ in total duration, gated with a Hanning window. The phase of the tone was alternated between presentations to minimise electrical artefacts from the recordings. Test frequencies ranged from 100 to $1500 \mathrm{~Hz}$. During each trial, 11 different frequencies were presented: 100, 200, 300, 400, 500, 600, 700, 800, 900, 1000 and $1500 \mathrm{~Hz}$; these frequencies covered the expected range of hearing of the studied species (Ladich and Fay, 2013). Sounds were attenuated in 6-dB steps beginning at the loudest level that could be generated at each frequency. Evoked potentials recorded by the electrode were fed through a TDT HS4-DB4 amplifier (10 000 gain) connected to an RP2.1, routed into the computer and averaged using BioSig software. To measure the evoked response at each level of each frequency, the signal was presented 500 times. Sound levels produced by the loudspeaker were calibrated with a Brüel and Kjær (Nærum, Denmark) hydrophone (model \#8101; sensitivity $-184 \mathrm{~dB}$ re $1 \mathrm{~V} / 1 \mu \mathrm{Pa}$; frequency response $0.1-200 \mathrm{kHz}$ ) placed in the experimental tank at the position normally occupied by the shark's head. The hydrophone was connected to a calibrated Brüel and Kjær 2610 amplifier that gave the absolute sound pressure level (SPL) at all frequencies and intensity levels tested. 
A 4096-point Fast Fourier Transform (FFT) was used to analyse the averaged AEP waveforms in the frequency domain. An auditory response was visually determined to be positive if the signal showed the presence of a peak at twice the stimulus frequency (e.g. $400 \mathrm{~Hz}$ peak when the signal played was $200 \mathrm{~Hz}$ ), which is typical of fish AEP (Mann et al., 2001; Parmentier et al., 2009). The background level was estimated from the AEP power spectrum with a window of $100 \mathrm{~Hz}$ around the doubling frequency (Casper and Mann, 2006). Thresholds were determined by both the averaged AEP trace and power spectrum, and were defined as the lowest sound level to show a repeatable AEP trace above the background noise, with an FFT peak at twice the stimulus frequency being at least $3 \mathrm{~dB}$ above the background level (Egner and Mann, 2005).

To ensure that the recorded AEP traces were not artefacts, controls were run by testing dead individuals in the experimental set-up. These dead sharks were embryonic specimens that were killed. No responses were recorded with dead sharks.

\subsection{Morphology of the inner ear}

One individual of each of the pre-hatchling stages (31, 33 and 34) was fixed in $5 \%$ formaldehyde for X-ray microtomography. A threedimensional study of the inner ear morphology and the brain was performed at the Centre for Microtomography of the University of Poitiers (France) in order to make a comparison between these different developmental stages. Specimens were treated with phosphomolybdic acid-dye stain $2.5 \%$ (PMA) for at least 5 days in a volume corresponding to $10 \%$ of the head volume. In addition, one juvenile that had been preserved in ethanol was rinsed and rehydrated in phosphate-buffered saline (PBS) for $24 \mathrm{~h}$ before being fixed in $5 \%$ formaldehyde for $24 \mathrm{~h}$, and then treated with PMA. X-ray microtomography of all specimens was performed according to the protocols reported by Boistel et al. (2011) and Zanette et al. (2014) using an RXsolutions (Annecy, France) EasyTom XL Duo microtomograph. The reconstruction was performed using the software XAct (RX solution) with the FDK algorithms. Three-dimensional (3D) images were produced in 16-bit and subsequently converted into 8-bit voxels using ImageJ (Abramoff et al., 2014). Three-dimensional processing and rendering according to the protocols reported by Zanette et al. (2014) were obtained after semi-automatic segmentation of the body, brain and inner ear using 'generated surface'. Direct volume renderings (iso-surface reconstruction) were used to visualise the subset of selected voxels of body, brain and inner ear in AVIZO 8.0.1 (FEI, VSG, Merignac, France, http://www.fei.com/software/ avizo3d/), after having used Material Statistics to obtain the volume measurements for all segmented components.

\section{5 | Histological study of the inner ear}

Three individuals of each of the pre-hatchling stages (31, 33 and 34) were used to compare the general morphology of their auditory apparatus as well as the development of the sensory hair cells of their saccular macula. First, one specimen of each stage was dehydrated in butanol, decalcified, embedded in paraffin and serially sectioned using a Reichert microtome (7 $\mu \mathrm{m}$ thickness). Each section was stained with Masson's Trichrome. The general morphology of the auditory apparatus was examined with a Wild M10 (Leica) binocular microscope. Sections were observed using an Olympus polarising microscope (Leica DM 100). Then, the otic capsules were removed from all the other individuals and fixed in 2-5 volumes of fixative solution containing $5 \%$ glutaraldehyde in a buffer composed of $0.2 \mathrm{M}$ sodium cacodylate, $0.25 \mathrm{M}$ sodium chloride, $10 \mathrm{~mm}$ calcium chloride and $1 \%$ sucrose at $\mathrm{pH} 7.4-7.6$ (Corwin, 1983). The otic capsules were stored for up to 1 month in refrigerated fixative. The saccular macula was then dissected from each of the otic capsules and post-fixed in $1 \%$ osmium tetroxide in the above buffer. These were dehydrated in an ethanol series, dried by the critical-point method with carbon dioxide using a Leica EM CPD300 critical point dryer, and examined with an ESEM Quanta $600\left(\mathrm{FEI}^{\mathrm{TM}}\right)$ scanning electron microscope (SEM) at $20.0 \mathrm{kV}$. Hair cells of the saccular macula were photographed using the SEM in order to make a comparison of their developmental stage.

No juveniles were used in this experiment because we were authorised to kill only one specimen out of five juveniles; other specimens had to be kept alive and returned to the Aquarium Dubuisson (Liège, Belgium). The only available specimen was used for the X-ray microtomography.

\section{6 | Statistical analyses}

The Bartlett's test was used to test the homogeneity of variances between groups of different developmental stages. As the assumption of homogeneity of variances was not always met, a non-parametric Kruskal-Wallis test was applied to compare auditory thresholds expressed in terms of SPLs between the different developmental stages. Eventually, non-parametric Mann-Whitney $U$-tests with Bonferroni adjustments were used to make pairwise comparisons of frequencies for which the significance level was met by the Kruskal-Wallis test. All statistical analyses were carried out with RStudio. Results are presented as means $\pm S D$. In addition to probabilities ( $P$-values), effect sizes of each statistical measure were estimated as the difference between medians of multiple groups using the web application Estimation Stats (http:// www.estimationstats.com; Ho et al., 2019) before inferences and conclusions were drawn.

\section{3 | RESULTS}

In agreement with previous statements, we do not claim the sharks were able to detect sound pressure. We obtained evoked potentials from all developmental stages tested; we simply report they were all exposed to the same sound pressure but show different responses, 
most probably because the particle acceleration related to each corresponding sound was different. It is, however, not possible to infer precisely the values of particle motion in the framework of this study (Rogers et al., 2016). At this stage of the knowledge, it is important to note we had a signal at the time of sound invoice for each of the 26 tested specimens, whereas we did not obtain any response from dead specimens. Moreover, specimen response was different according to the used frequency. These responses were coherent within specimens being at the same stage.

Audiograms showed a gradual increase in the frequency range with increasing age (Fig. 1): the detectable frequencies ranged from 100 to $300 \mathrm{~Hz}$ in stage 31 (pre-hatching stage), from 100 to $400 \mathrm{~Hz}$ in stages 33 and 34 (hatching stage), and from 100 to $600 \mathrm{~Hz}$ in juveniles. No response was detectable at 700, 800, 900, 1000 and $1500 \mathrm{~Hz}$ for any stage of development.

In the audiograms expressed in SPLs, all developmental stages (except stage 31 ) showed their best hearing sensitivity at the highest detectable frequency (Fig. 1a).

Hearing thresholds at $200 \mathrm{~Hz}$ were significantly different (Kruskal-Wallis test, $\chi^{2}{ }_{4}=18.15, P=0.001$ ) between stages 31 and 33 (Mann-Whitney $U$-test, $P=0.027$ ), and between stages 31 and 34 (Mann-Whitney U-test, $P=0.02$ ). At $300 \mathrm{~Hz}$ (KruskalWallis test, $\chi^{2}{ }_{4}=13.37, P=0.009$ ) and $400 \mathrm{~Hz}$ (Kruskal-Wallis test, $\chi_{4}^{2}=10.96, P=0.012$ ), only stages 33 and 34 differed significantly $(300 \mathrm{~Hz}$ : Mann-Whitney U-test, $P=0.048 ; 400 \mathrm{~Hz}$ : Mann-Whitney $U$-test, $P=0.046$ ). No other significant difference was found at any tested frequency between the different stages (Kruskal-Wallis test, $\chi^{2}{ }_{4}=0.54-7.7, P=0.052-.46$ ). Effect size calculation confirmed that stages show little differences in their auditory thresholds when comparing them for a given frequency. The effect sizes were small as they ranged from 0 to $7 \mathrm{~dB}$ re: $1 \mu \mathrm{Pa}$. Larger values were only found at $200 \mathrm{~Hz}$ between stages 31 and 34 (11 dB re: $1 \mu \mathrm{Pa}$ ), and at $300 \mathrm{~Hz}$ between stages 33 and $34(9 \mathrm{~dB}$ re: $1 \mu \mathrm{Pa}$; Table 1$)$.

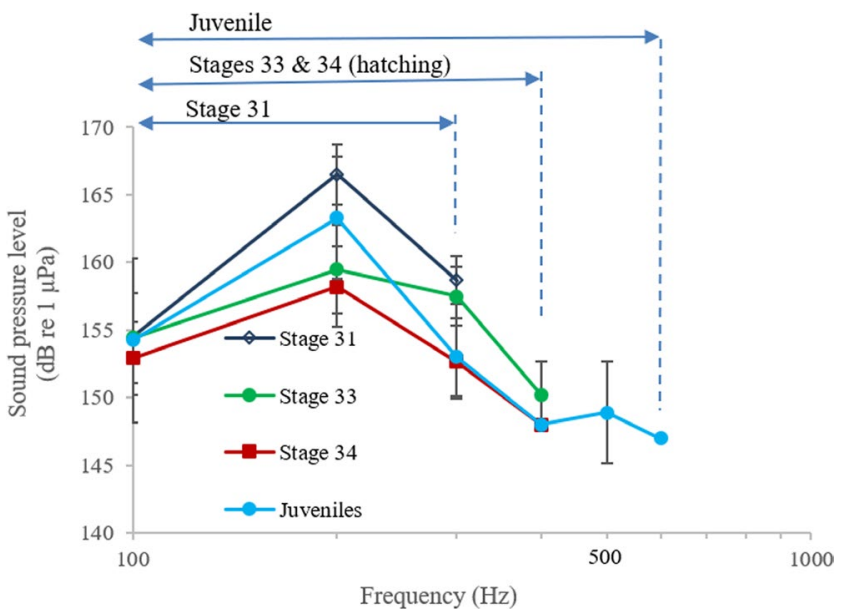

FIGURE 1 Hearing threshold mean ( \pm SD) of the different studied stages in Scyliorhinus canicula. Responses expressed in terms of sound pressure level (SPL). Double arrows help to visualise the increase in the frequency range
In the next step, we followed the macroscopic development of the brain and inner ear. At the pre-hatching stage, all the structures classically found in the inner ear (otolithic chambers, the three semi-circular canals and their ampullae) are already present. Only the sizes of these inner ear structures seem to be different between the developmental stages (Fig. 2). The five regions commonly found in the brain of elasmobranchs are also already visible at the pre-hatching stage (Fig. 2).

All these data support the fact that we were able to detect hearing abilities, but histological examinations were required to refine the results. The different sensory epithelia (i.e. crista in the ampullae, maculae in the otolithic chambers, and macula neglecta in the posterior canal duct) are already present (Figs 3 and 4), and clearly increase in size between pre-hatching and hatching stages. Although this comparison needs to be carefully addressed, it seems that the number of sensory hair cells also increases with age. These hair cells also become more elongated, uniform and their nucleus is centred (Fig. 3). Moreover, a layer of non-sensory supporting cells appears to be more structured at hatching than at pre-hatching stage (Fig. 3).

Interestingly, the increase of auditory capabilities with age is also supported by the development of the saccular macula sensory hair cells observed using the SEM (Fig. 5). Hair cells are mainly composed of a single kinocilium and only a few short stereocilia at pre-hatching stage (Fig. 5). At the hatching stage, the saccular macula contains numerous hair cells with well-developed stereocilia (Fig. 5). We were not able to make a quantitative comparison of sensory hair cells between the different developmental stages.

\section{4 | DISCUSSION}

In Carcharhinus melanopterus and Raja clavata, the size of the macula neglecta and the number of hair cells grow with age (Corwin, 1981b, 1983). About $80 \%$ of the number of macula neglecta hair cells in the adults of $C$. melanopterus are produced post-embryonically (Corwin, 1981b). In this study, the youngest organisms (stage 31, 3-4 months before hatching) already possess the three otolithic chambers, the three semi-circular canals as well as their ampullae, namely all features allowing them to detect sounds from 100 to $300 \mathrm{~Hz}$. Juveniles are able to detect sounds from 100 to $600 \mathrm{~Hz}$. Only the size of these structures increases with age. Our morphological study based on both 3D reconstructions of the inner ear and histological sections supports the hypothesis that the development of the frequency range takes place simultaneously with the growth of the inner ear (Figs 3 and S1) and the brain (Fig. 2). This improvement of inner ear sensitivity takes place not only inside the egg but also after hatching, as juveniles possess better hearing abilities than embryos. However, the development of other anatomical elements such as nerves, parietal fossa (Bullock and Corwin, 1979), statoconia (Hanson et al., 1990; Lychakov et al., 2000) or lateral line (Higgs and Radford, 2013) can be involved in the detection of particle motion, and all deserve additional studies.

However, the development only appears to be related to the frequency range. Older specimens do not have improved sensitivity 
TABLE 1 Summary of effect size calculated as the difference between medians and exact $P$-values of all pairwise comparisons made using Mann-Whitney $U$-tests comparing SPL values between different developmental stages for all tested frequencies

\begin{tabular}{|c|c|c|c|c|c|c|c|}
\hline Group 1 & Group 2 & $\begin{array}{l}\text { Group } 1 \\
N\end{array}$ & $\begin{array}{l}\text { Group } 2 \\
N\end{array}$ & Difference & ci_lower_limit & ci_upper_limit & $P$-value \\
\hline \multicolumn{8}{|l|}{$100 \mathrm{~Hz}$} \\
\hline Stage 34 & Juveniles & 7 & 5 & 0 & -5.5 & 0 & 1 \\
\hline Stage 31 & Stage 34 & 7 & 7 & 0 & 0 & 0 & 1 \\
\hline Stage 31 & Juveniles & 7 & 5 & 0 & -5.5 & 0 & 1 \\
\hline Stage 33 & Stage 34 & 7 & 7 & 0 & -10.5 & 0 & 1 \\
\hline \multicolumn{8}{|l|}{$200 \mathrm{~Hz}$} \\
\hline Stage 31 & Stage 33 & 7 & 7 & -5 & -5 & -5 & 0.027 \\
\hline Stage 34 & Juveniles & 7 & 5 & 6 & 6 & 6 & 0.921 \\
\hline Stage 33 & Stage 34 & 7 & 7 & -6 & -6 & -6 & 0.373 \\
\hline \multicolumn{8}{|l|}{$300 \mathrm{~Hz}$} \\
\hline Stage 31 & Stage 33 & 3 & 7 & 4 & -4 & 4 & 1 \\
\hline Stage 34 & Juveniles & 7 & 5 & 5 & -5 & 5 & 1 \\
\hline Stage 31 & Stage 34 & 3 & 7 & -5 & -14 & -5 & 0.844 \\
\hline Stage 33 & Juveniles & 7 & 5 & -4 & -9 & -4 & 0.14 \\
\hline Stage 31 & Juveniles & 3 & 5 & 0 & -9 & 0 & 1 \\
\hline Stage 33 & Stage 34 & 7 & 7 & -9 & -14 & -14 & 0.048 \\
\hline \multicolumn{8}{|l|}{$400 \mathrm{~Hz}$} \\
\hline Stage 34 & Juveniles & 3 & 5 & 0 & 0 & 0 & 1 \\
\hline Stage 33 & Juveniles & 2 & 5 & 0 & 0 & 0 & 1 \\
\hline Stage 33 & Stage 34 & 2 & 3 & & & & \\
\hline
\end{tabular}

Missing values result from low sample size and/or low variability within a group. $N$ corresponds to the number of specimens. Bold data refers to results that were significantly different.

and do not have a better threshold for a given frequency. Changes observed in the maculae and the larger frequency range in older $S$. canicula are consistent with observations on C. melanopterus and R. clavata (Corwin, 1981b, 1983). The development of a broader spectrum of detected frequencies during development in the egg was also found in the clownfish Amphiprion ephippium and Amphiprion rubrocinctus (Simpson et al., 2005).

The shark is sensitive only to particle motions associated with a sound field, and not sound pressure. Studies dealing with particle motions are scarce mainly because we lack appropriate equipment and expertise. Methods to measure and model the particle motion are still needed to understand better the acoustic communication, and the potential effects of noise on aquatic fauna (Nedelec et al.,
2016; Rogers et al., 2016). We provide hearing data in relation to near field sound pressure. We are aware this method has the potential to introduce experimental error because it does not perfectly mirror particle motions (Nedelec et al., 2016; Rogers et al., 2016), and deviations between sound pressure and particle motion can be high in the near field, i.e. near sound sources (Nedelec et al., 2016). However, this error would be minimal because we always use the same species in the same experimental approach and in the same acoustic environment (Ladich and Fay, 2013; Rogers et al., 2016; Popper et al., 2019). Size could be a problem in testing the hearing abilities in fish (Rogers et al., 2016), but sharks do not have swim bladders and consequently do not introduce acoustic scatterer in the tank, limiting variation in the near sound field. 


\section{WILEY - Journal of Anatomy}

\section{Dorsal}

Stage 31

Stage 33

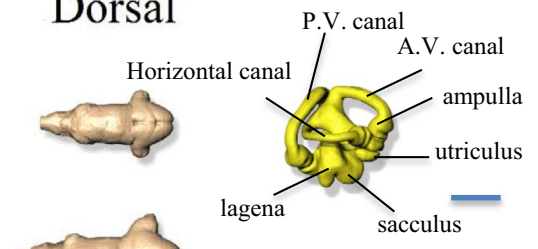

ANATOMICAL

\section{Lateral}
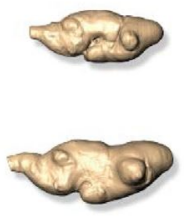

Stage 34
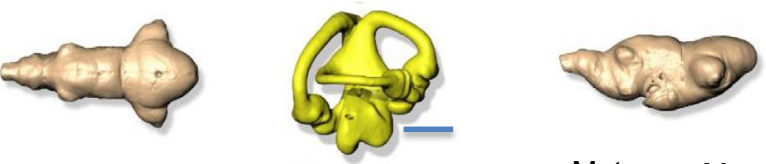
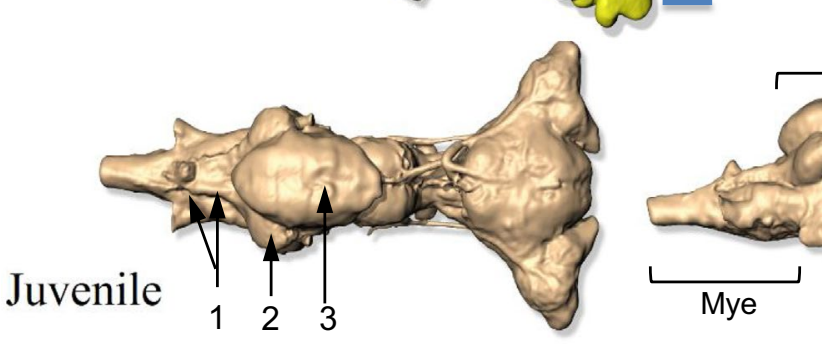

Mye
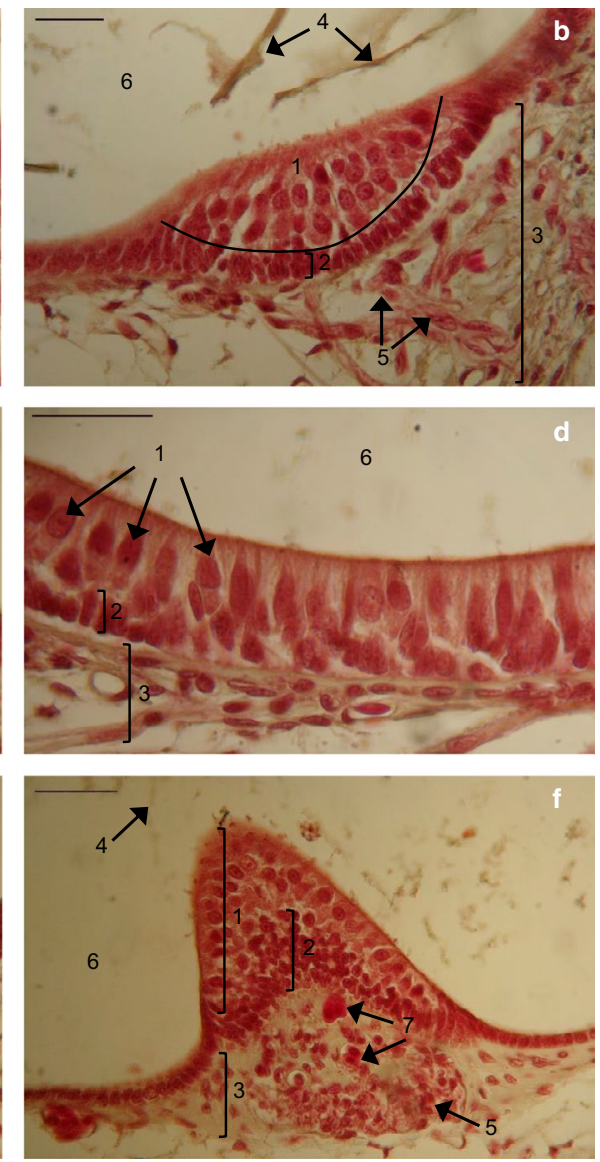

FIGURE 3 Comparisons between stages 31 (left) and 34 (right) of the maculae in the sacculus ( $a, b)$, in the lagena (c, d), and of the crista in ampullae of semi-circular canals (e, f). 1: Hair cells; 2: supporting cells; 3 : stalk of the crista (connective tissue); 4: cupula; 5 : nerve terminals; 6: lumen; 7: blood vessel. Scale bars: $30 \mu \mathrm{m}$
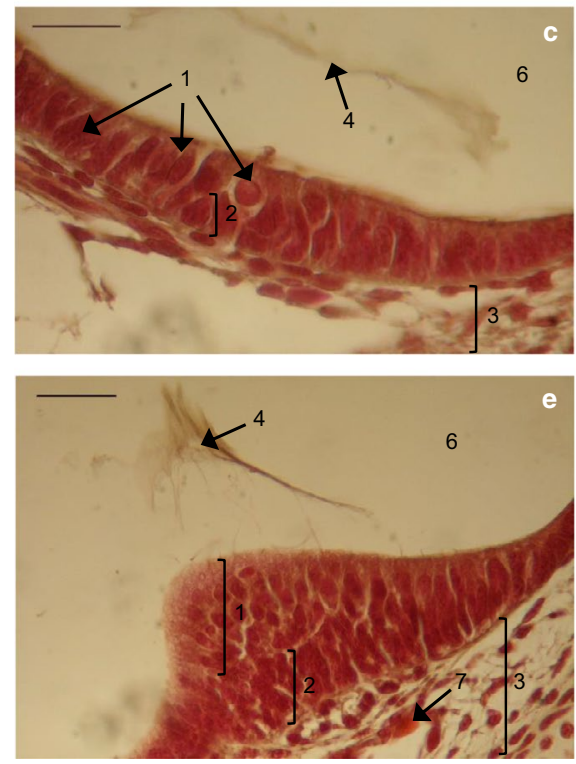

At this stage, we are not fully interested in knowing what the real threshold is but how it evolves in parallel with inner ear development. Many studies have shown there is great variability in sound level detection within the same species determined by different investigators (Popper et al., 2019), but it is not the case for the frequency range. Five-seven specimens per developmental stage were investigated. Within each stage, these specimens provided the same kind of response, i.e. they were able to detect some frequencies or 
ANATOMICAL

1

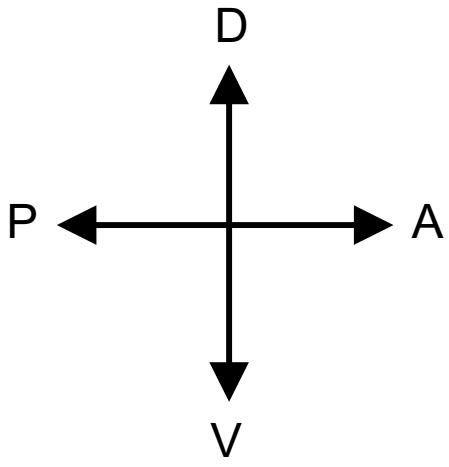

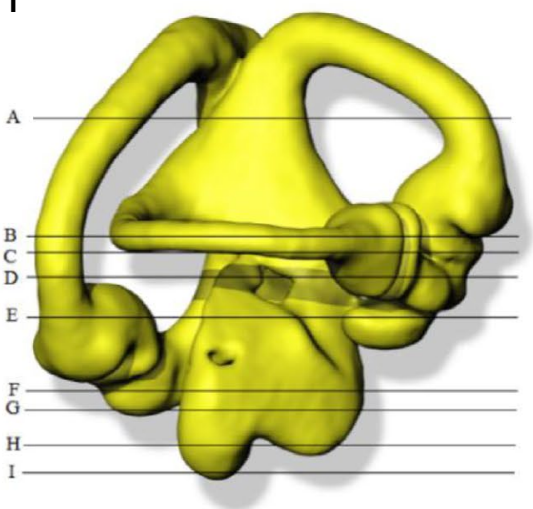

Journal of Anatomy

2

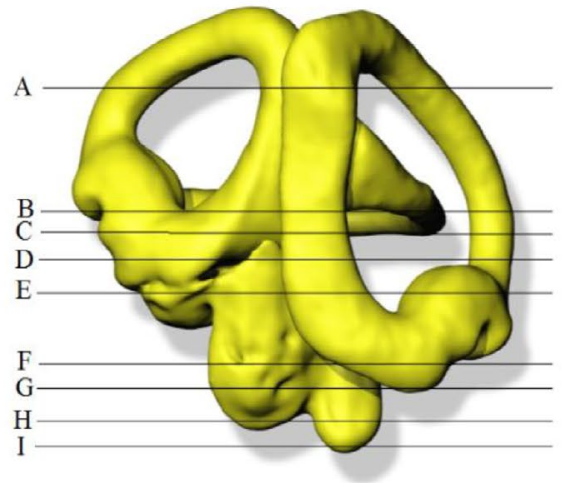

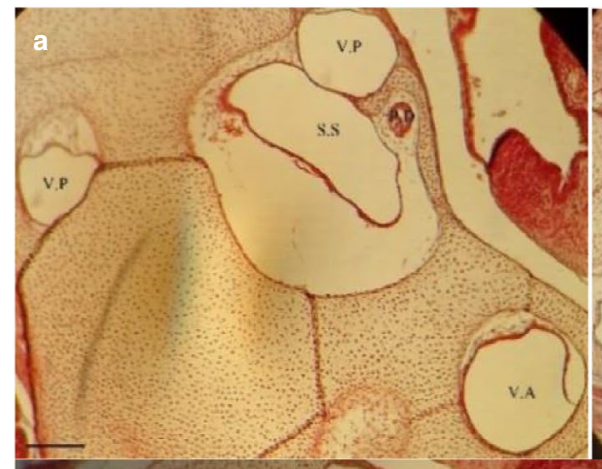
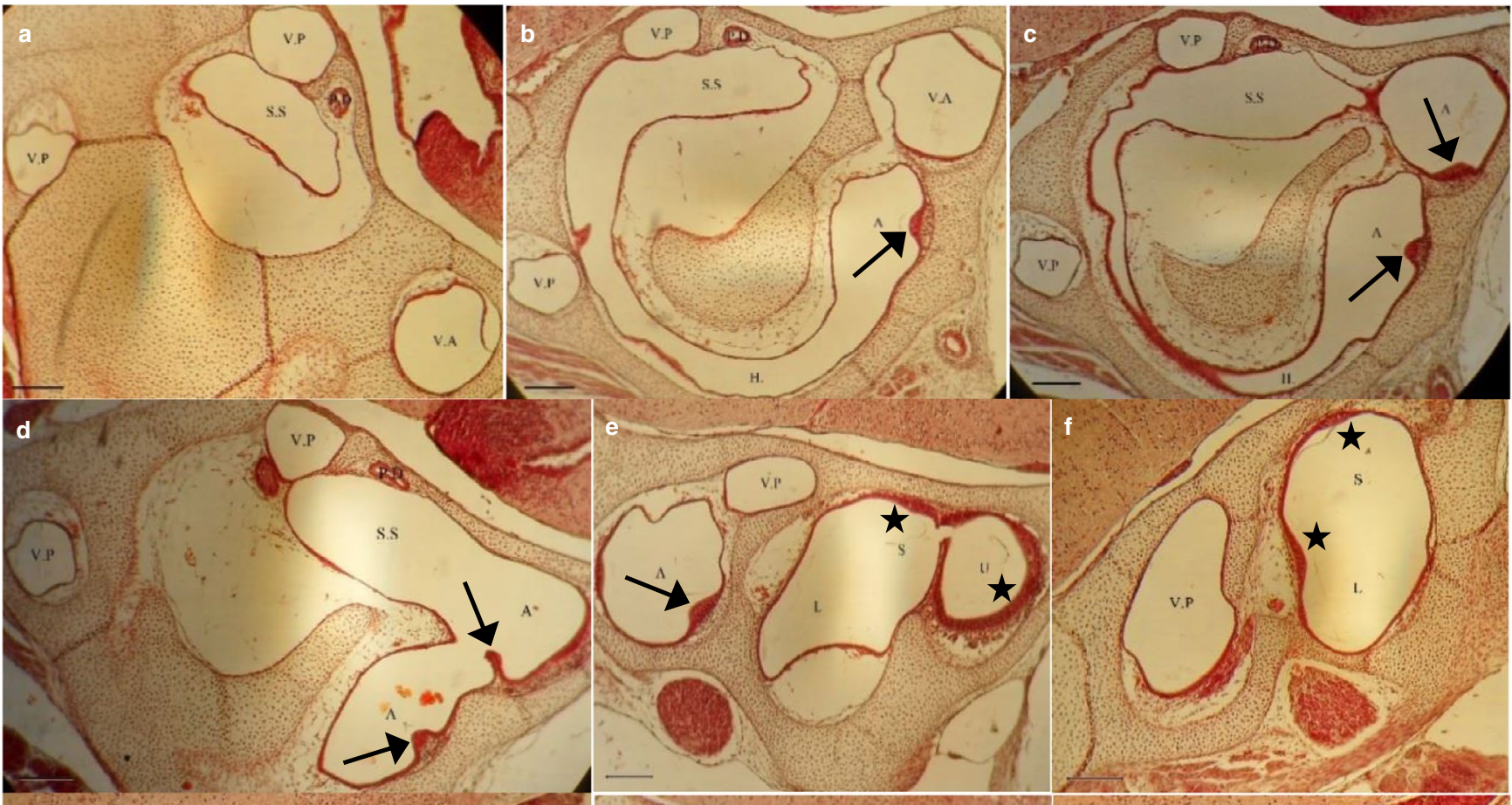

g
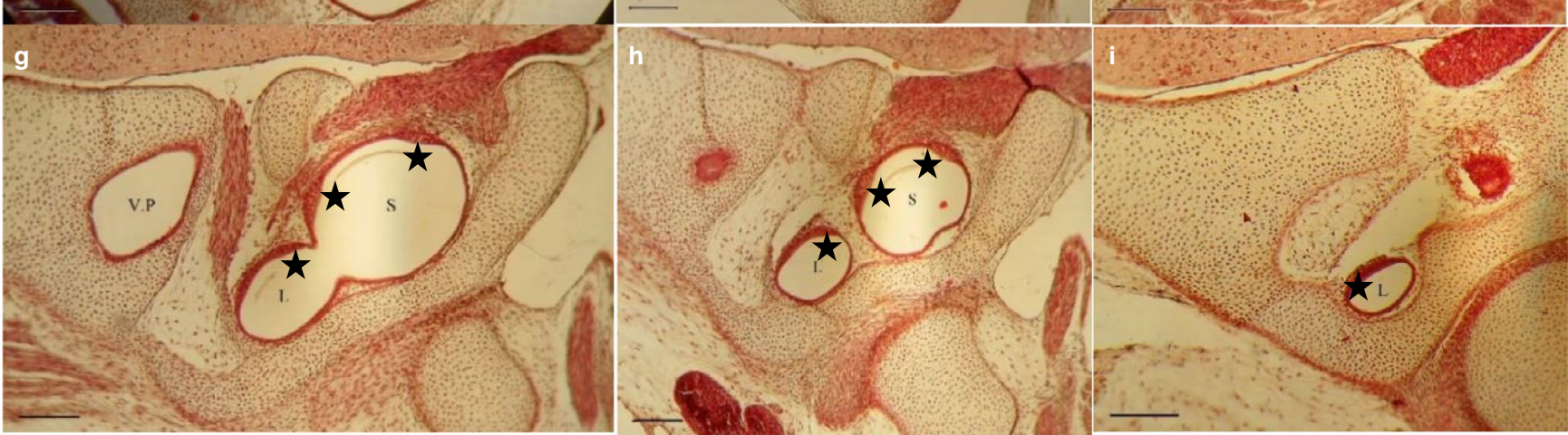

FIGURE 4 Frontal histological sections of the right inner ear in Scyliorhinus canicula at stage 31. Letters refer to the section indicated on the 3D reconstruction (1: lateral view; and 2: medial view) of the inner ear obtained by X-ray microtomography. Each anatomical feature is labelled as follows: A, ampulla; L, lagena; H., horizontal semi-circular canal; P.D., posterior canal duct; S, sacculus; S.S., sinus superior; U, utriculus; V.A., vertical anterior semi-circular canal; V.P., vertical posterior semi-circular canal. Arrows in b, c, d, e indicate cristae in the ampullae of semi-circular canals. Stars in e, $\mathrm{f}, \mathrm{g}, \mathrm{h}$, i indicate the saccular, lagenar or utricular maculae. Orientation is given by the notations: A, anterior; D, dorsal; P, posterior; V, ventral. Scale bars: $150 \mu \mathrm{m}$ 

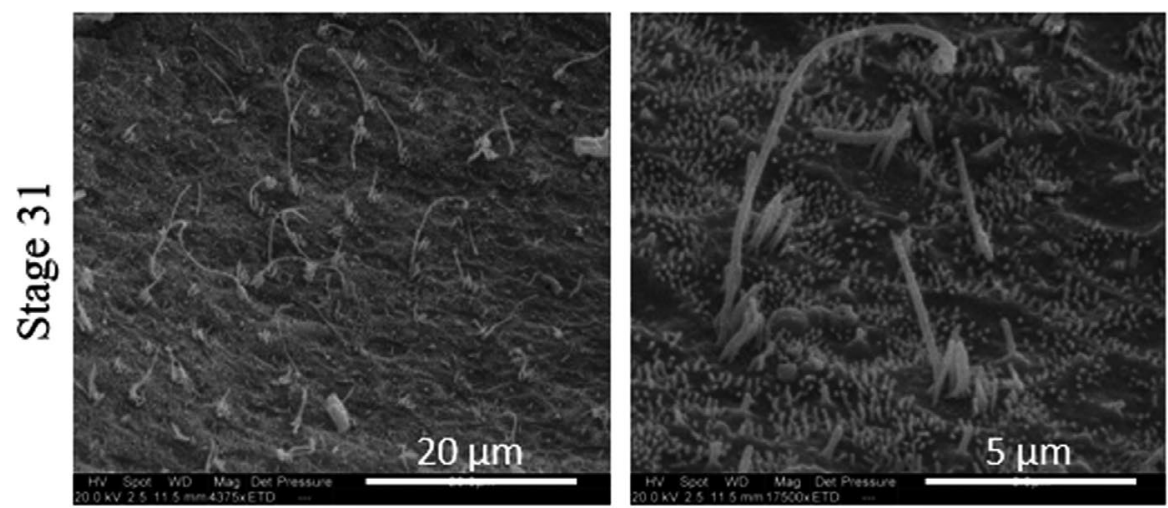

FIGURE 5 Scanning electron

micrograph (SEM) of macula sensory hair cells in Scyliorhinus canicula at stages 31 (3-4 months before hatching), 33 and stage 34 (hatching). Stage 31 shows some hair cells with their well-developed kinocilium and short stereocilia. Stage 34 shows hair cells with well-developed stereocilia
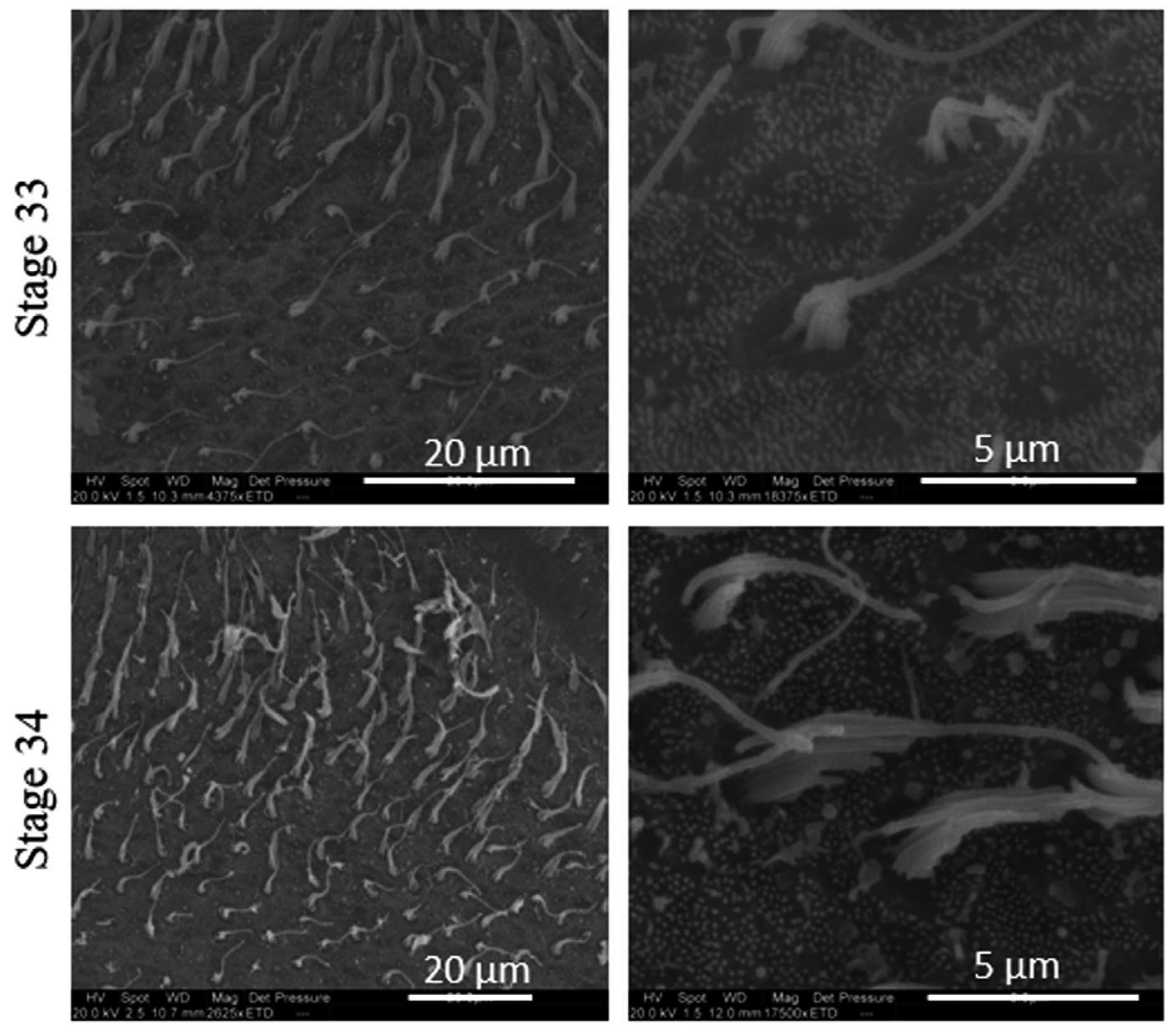

not. Our results highlight the ear development in sharks corresponds to an enlargement of the frequency bandwidth.

\section{5 | CONCLUSION}

This study shows that the shark S. canicula is able to detect sounds within its eggshell, and the development of hearing capacities takes place simultaneously with the development of sensory epithelia. It has the main advantage of highlighting that physiological experiments on auditory abilities can be done before hatching in these oviparous species. It should provide new insight on the study of hearing development.

\section{ACKNOWLEDGEMENTS}

We thank Isabelle Habsch (Uliege) for help with the histological sections; Bruno Parmentier for help with the preparation of the experimental steel tank. We also thank the Sea Life Centre of Blankenberge, the Aquarium of Antwerp and the Roscoff biology station in France for providing eggs of Scyliorhinus canicula and the team of the Aquarium-Museum of Liège for providing juveniles. Two anonymous referee and our editor provide interesting remarks improving this study.

\section{CONFLICTS OF INTEREST}

The authors do not have any conflicts of interest to declare.

\section{AUTHORS' CONTRIBUTIONS}

EP conceived and designed the experiments. $\mathrm{OC}$ and $\mathrm{MB}$ performed the hearing experiments. RB performed the $C T$ scan and $3 D$ constructions. OC, MB, PC performed histological study. FB performed statistical analysis. EP and OC wrote the manuscript; other authors provided editorial advice.

\section{DATA AVAILABILITY STATEMENT}

The data that support the findings of this study are available from the corresponding author upon reasonable request. 


\section{ORCID}

Eric Parmentier iD https://orcid.org/0000-0002-0391-7530

\section{REFERENCES}

Abramoff, M.D., Magalhaes, P.J. and Ram, S.J. (2014) Image processing with Image J. Biophotonics International, 11, 36-42.

Ballard, W., Mellinger, J. and Lechenault, H. (1993) A series of normal stages for development of Scyliorhinus canicula the lesser spotted dogfish (Chondrichthyes : Scyliorhinidae). Journal of Experimental Zoology, 267, 318-336.

Barber, V.C. and Emerson, C.J. (1980) Cell and tissue scanning electron microscopic observations on the inner ear of the skate, Raja oceilata. Cell and Tissue Research, 215, 199-215.

Boistel, R., Swoger, J., Krzic, U., Fernandez, V., Gillet, B. and Reynaud, E.G. (2011) The future of three-dimensional microscopic imaging in marine biology. Marine Ecology, 32, 438-452.

Bullock, T.H. and Corwin, J.T. (1979) Acoustic evoked activity in the brain in sharks. Journal of Comparative Physiology A, 129, 223-234.

Casper, B.M. and Mann, D.A. (2006) Evoked potential audiograms of the nurse shark (Ginglymostoma cirratum) and the yellow stingray (Urobatis jamaicensis). Environmental Biology of Fishes, 76, 101-108.

Colleye, O., Ovidio, M., Salmon, A. and Parmentier, E. (2013) Contribution to the study of acoustic communication in two Belgian river bullheads (Cottus rhenanus and C. perifretum) with further insight into the sound-producing mechanism. Zoology, 10, $1-14$.

Corwin, J.T. (1981a) Peripheral auditory physiology in the lemon shark: Evidence of parallel otolithic and non-otolithic sound detection. Journal of Comparative Physiology A, 142, 379-390.

Corwin, J.T. (1981b) Postembryonic production and aging of inner ear hair cells in sharks. The Journal of Comparative Neurology, 201, 541-553.

Corwin, J.T. (1983) Postembryonic growth of the macula neglecta auditory detector in the ray, Raja clavata: continual increases in hair cell number, neural convergence, and physiological sensitivity. The Journal of Comparative Neurology, 217, 345-356.

Corwin, J.T. (1989) Functional anatomy of the auditory system in sharks and rays. Journal of Experimental Zoology, 252, 62-74.

Corwin, J.T. and Northcutt, G. (1982) Auditory centers in the elasmobranch brain stem: deoxyglucose autoradiography and evoked potential recording. Brain Research, 236, 261-273.

Demski, L.S., Gerald, J.W. and Popper, A.N. (1973) Central and peripheral mechanisms of teleost sound production. American Zoologist, 13, 1141-1167.

Diez, J.M. and Davenport, J. (1987) Embryonic respiration in the dogfish (Scyliorhinus canicula L.). Journal of the Marine Biological Association of the United Kingdom, 67, 249-261.

Egner, S.A. and Mann, D.A. (2005) Auditory sensitivity of sergeant major damselfish Abudefduf saxatilis from post-settlement juvenile to adult. Marine Ecology Progress Series, 285, 213-222.

Foulley, M.-M. and Mellinger, J. (1980). Etude chronologique, structurale et biométrique de l'œuf et de son développement chez la petite roussette (Scyliorhinus canicula) élevée en eau de mer artificielle. Reproduction Nutrition Développement, 26, 1835-1848.

Gans, C. (1992) An overview of the evolutionary biology of hearing. In: The Evolutionary Biology of Hearing (eds Webster, D.B., Fay, R.R. and Popper, A.N.), pp. 3-13. New York: Springer.

Hanson, M., Westerberg, H. and Öblad, M. (1990) The role of magnetic statoconia in dogfish (Squalus Acanthias). The Journal of Experimental Biology, 151, 205-218.

Higgs, D.M. and Radford, C.A. (2013) The contribution of the lateral line to 'hearing' in fish. Journal of Experimental Biology, 216(8), 1484-1490.
Ho, J., Tumkaya, T., Aryal, S., Choi, H. and Claridge-Chang, A. (2019) Moving beyond $P$ values: data analysis with estimation graphics. Nature Methods, 16, 565-566.

Hueter, R.E., Mann, D.A., Maruska, K.P., Sisneros, J.A. and Demski, L.S. (2004) Sensory biology of elasmobranchs. In: Biology of Sharks and Their Relatives (eds Carrier, J.C., Musick, J.A. and Heithaus, M.R.), pp. 325-368. Boca Raton, Florida: CRC Press.

Kéver, L., Colleye, O., Herrel, A., Romans, P. and Parmentier, E. (2014) Hearing capacities and otolith size in two ophidiiform species (Ophidion rochei and Carapus acus). Journal of Experimental Biology, 217, 2517-2525.

Kormanik, G.A. (1993) lonic and osmotic environment of developing elasmobranch embryos. Environmental Biology of Fishes, 38, 233-240.

Ladich, F. and Fay, R.R. (2013) Auditory evoked potential audiometry in fish. Review in Fish Biology and Fisheries, 23, 317-364.

Lovell, J.M., Findlay, M.M., Harper, G.M. and Moate, R.M. (2007) The polarization of hair cells from the inner ear of the lesser spotted dogfish Scyliorhinus canicula. Journal of Fish Biology, 70, 362-373.

Lowenstein, O. and Roberts, T.D.M. (1951) The localization and analysis of the responses to vibration from the isolated elasmobranch labyrinth; a contribution to the problem of the evolution of hearing in vertebrates. Journal of Physiology, 114, 471-489.

Löwenstein, O. and Sand, A. (1940) The individual and integrated activity of the semicircular canals of the elasmobranch labyrinth. Journal of Physiology, 99, 89-101.

Lychakov, D.V., Boyadzhieva-Mikhailova, A., Christov, I. and Evdokimov, I.I. (2000) Otolithic apparatus in Black Sea elasmobranchs. Fisheries Research, 46, 27-38.

Maisey, J.G. (2001) Remarks on the inner ear of elasmobranchs and its interpretation from skeletal labyrinth morphology. Journal of Morphology, 250, 236-264.

Mann, D.A., Higgs, D.M., Tavolga, W.N., Souza, M.J. and Popper, A.N. (2001) Ultrasound detection by clupeiform fishes. Journal of the Acoustical Society of America, 109, 3048-3054.

Mellinger, J. (1994) L'oeuf de roussette (Scyliorhinus canicula) incubé au laboratoire : un matériel de recherche pour l'embryologiste, l'éthologiste, le physiologiste. Ichtyophysiologica Acta, 17, 9-27.

Mills, M., Rasch, R., Siebeck, U.E. and Collin, S.P. (2011) Exogenous material in the inner ear of the adult Port Jackson shark, Heterodontus portusjacksoni (Elasmobranchii). Anatomical Record, 294, 373-378.

Montgomery, J.C., Jeffs, A., Simpson, S.D., Meekan, M.G. and Tindle, C. (2006) Sound as an orientation clue for the pelagic larvae of reef fish and crustaceans. Advances in Marine Biology, 51, 143-196.

Nedelec, S.L., Campbell, J., Radford, A.N., Simpson, S.D. and Merchant, N.D. (2016) Particle motion: the missing link in underwater acoustic ecology. Methods in Ecology and Evolution, 7, 836-842.

Parmentier, E., Colleye, O. and Mann, D. (2009) Hearing ability in three clownfish species. Journal of Experimental Biology, 212, 2023-2026.

Popper, A.N. and Fay, R.R. (2011) Rethinking sound detection by fishes. Hearing Research, 273, 25-36.

Popper, A.N., Hawkins, A.D., Sand, O. and Sisneros, J.A. (2019) Examining the hearing abilities of fishes. Journal of the Acoustical Society of America, 146, 948-955.

Retzius, G. (1884). Das Gehörorgan der Reptilien, der Vögel und der Säugethiere (Vol. 2). In: Das Gehörorgan der Wirbelthiere: MorphologischhistologischeStudien. Stockholm: Samson \& Wallin.

Rogers, P.H., Hawkins, A.D., Popper, A.N., Fay, R.R. and Gray, M.D. (2016) Parvulescu revisited: small tank acoustics for bioacousticians BT. In: The Effects of Noise on Aquatic Life II (eds Popper, A.N. and Hawkins, A.), pp. 933-941. New York: Springer.

Simpson, S.D., Yan, H.Y., Wittenrich, M.L. and Meekan, M.G. (2005) Response of embryonic coral reef fishes (Pomacentridae: Amphiprion spp.) to noise. Marine Ecology Progress Series, 287, 201-208. 
Tester, A.L., Kendall, J.I. and Milisen, W.B. (1972) Morphology of the ear of the shark genus Carcharhinus, with particular reference to the macula neglecta. Pacific Science, 26, 264-274.

Zanette, I., Daghfous, G., Weitkamp, T., Gillet, B. and Adriaens, D. (2014) Looking Inside marine organisms with magnetic resonance and X-ray imaging. In: Imaging Marine Life: Macrophotography and Microscopy Approaches for Marine Biology (ed. Reynaud, E.G.), pp. 123-184. Hoboken: Wiley-Blackwell.
How to cite this article: Parmentier E, Banse M, Boistel R, Compère $P$, Bertucci $F$, Colleye $O$. The development of hearing abilities in the shark Scyliorhinus canicula. J. Anat. 2020;00:1-10. https://doi.org/10.1111/joa.13212 